[Article]

\title{
碱性离子液体催化合成三羟甲基丙烷
}

\author{
龙金星 ${ }^{1, *}$ 袁正求 ${ }^{1}$ 马 浩 $^{2}$ 舒日洋 ${ }^{1}$ 李雪辉 ${ }^{2, *}$ \\ ( 1 中国科学院广州能源研究所, 中国科学院可再生能源重点实验室, 广州 510640; \\ 2华南理工大学化学与化工学院, 广州 510640)
}

\begin{abstract}
摘要: 以碱性离子液体为催化剂, 构建了一种新型、高效的合成三差圣基丙烷(TMP)的方法. 系统考察了催化 剂类型、催化剂用量、反应温度、反应时间、甲醛与正丁醛用量比等因素对三羟甲基丙烷分离收率的影响. 研究 结果表明: 碱性离子液体的催化性能与其碱强度息息相关, 碱性越强、催化活性越高. 最优条件下, 经离子液体 [bmim]OH 催化后, 可得到 84\% 的 TMP 分离收率, 这一结果优于传统的有机无机碱催化体系且成功规避了传统 碱催化合成 TMP 过程中繁琐的除盐过程、降低了过程能耗. 此外, 离子液体催化剂和未反应的丁醛均表现了良 好的重复使用性能.
\end{abstract}

关键词: 三羟甲基丙烷；离子液体；碱性强度；Cannizzaro 缩合；重复使用性 中图分类号: 0643

\section{Catalytic Synthesis of Trimethylolpropane in the Presence of Basic Ionic Liquid}

\author{
LONG Jin-Xing ${ }^{1, *} \quad$ YUAN Zheng-Qiu ${ }^{1} \quad$ MA Hao $^{2} \quad$ SHU Ri-Yang ${ }^{1} \quad$ LI Xue-Hui ${ }^{2, *}$ \\ ('Key Laboratory of Renewable Energy, Guangzhou Institute of Energy Conversion, Chinese Academy of Sciences, \\ Guangzhou 510640, P. R. China; ${ }^{2}$ School of Chemistry and Chemical Engineering, \\ South China University of Technology, Guangzhou 510640, P. R. China)
}

\begin{abstract}
Ionic liquid (IL) catalyst attracts increasing attention during last few decades due to its excellent advantages of both homogeneous and heterogeneous catalyst. Here, a novel and efficient strategy for the production of trimethylolpropane (TMP) is proposed with basic IL catalysts. The catalytic activities of the IL catalysts are investigated. The effects of catalyst dosage, reaction temperature, time, and the molar ratio of the reactants are also studied. The results show that the basicity of the IL catalyst has a significant effect on the catalytic activity, where stronger basicity indicates higher catalytic activity. The IL 1-butyl-3-methyl imidazolium hydroxyl $([\mathrm{bmim}] \mathrm{OH})$ is proven to be the most efficient catalyst where more than $84 \%$ isolated yield of TMP was obtained under optimized conditions. Furthermore, both the IL catalyst and butyraldehyde show excellent recyclability. Moreover, this IL catalytic system avoids the inevitable desalination encountered by current processes utilizing inorganic alkali catalysts.
\end{abstract}

Key Words: Trimethylolpropane; Ionic liquid; Basic strength; Cannizzaro condensation; Recyclability

\section{Introduction}

Trimethylolpropane (TMP), a polyol containing $\alpha$-hydroxy- methyl and neopentyl functional groups, has been regarded as an important intermediate in the organics industry. ${ }^{1}$ Generally, TMP

Received: September 30, 2014; Revised: December 10, 2014; Published on Web: December 10, 2014.

*Corresponding authors. LONG Jin-Xing, Email: longjx@ms.giec.ac.cn; Tel: +86-20-87048614. LI Xue-Hui, Email: cexhli@scut.edu.cn.

The project was supported by the National Natural Science Foundation of China $(51306191,21336002)$ and Doctoral Fund of Ministry of Education of China (20130172110043).

国家自然科学基金(51306191, 21336002)及教育部博士点基金(20130172110043)资助项目

(c) Editorial office of Acta Physico-Chimica Sinica 
is synthesized via a two-step process, namely, an Aldol condensation of formaldehyde and butyraldehyde followed by a Cannizzaro condensation ${ }^{2}$ or catalytic hydrogenation. ${ }^{3,4}$ The catalytic hydrogenation method usually suffers from high reaction temperatures and high $\mathrm{H}_{2}$ pressure, requiring robust equipment for the dangerous operating conditions. In contrast, the Cannizzaro condensation is more popular because of its gentle reaction conditions and efficient product separation. Conventional alkalis, such as $\mathrm{NaOH}, \mathrm{KOH}, \mathrm{Ca}(\mathrm{OH})_{2}$, and $\mathrm{Na}_{2} \mathrm{CO}_{3}$, were proven to be efficient catalysts for this process, and $70 \%-80 \%$ yields have been demonstrated. ${ }^{1,2}$ However, the homogeneous catalysts are corrosive and difficult to recover. Heterogeneously catalyzed processes generally suffer from high catalyst/substrate molar ratios and unevenly distributed active centers. ${ }^{5}$ Furthermore, the post-separation and product purifaction are tedious and laborintensive (especially desalination).

As a novel catalyst, ionic liquid (IL) combines the advantages of both homogenous and heterogeneous catalysts: high acid or alkali strength, uniform catalytic active centers, easy separation, and recyclability. ${ }^{5-7}$ Therefore, ILs have been widely used in catalytic processes, such as material synthesis, organic catalysis, and more recent biomass conversion. ${ }^{8-15}$ In 2005, Ranu and Banerjee $^{16}$ first reported that the Michael addition process could be promoted efficiently in the presence of the basic IL [bmim] OH. More than $90 \%$ product yield was achieved for all active methylene compounds examined. Inspired by this work, many basecatalyzed processes have been extensively investigated. ${ }^{17-21}$ For example, $\mathrm{Xu}$ and coworkers ${ }^{18}$ show that $73 \%-93 \%$ of product yield could be obtained during the Markovnikov addition reaction between alkyl-substituted imidazolium and the unsaturated ester with IL $[\mathrm{bmim}] \mathrm{OH}$ catalyst. Yang et al. ${ }^{19}$ also found that this functionalized IL shows much better catalytic activity than conventional inorganic and organic alkali catalysts in the aza-Michael addition reaction. Basic ILs demonstrate excellent activity for the Knoevenagel reaction and the Perkin reaction, as well. For instance, greater than $85 \%-95 \%$ substituted alkenes were produced at room temperature for reaction time of $10-30 \mathrm{~min}^{21}$ Recently, it has also been reported that this IL exhibits excellent catalytic performance in the facile and efficient synthesis of piperido $3^{\prime}, 4^{\prime}$ : 5,6 pyrano $2,3-\mathrm{d}$ pyrimidinones ${ }^{20}$ and the regioselective synthesis of thiazolidin-4-one derivatives. ${ }^{22}$ However, few investigations focused on the TMP synthesis, a typical base-catalyzed process. In light of evidence supporting the excellent catalytic activity of basic IL on the abovementioned processes, we report a novel and efficient process for TMP production at mild reaction conditions utilizing these efficient ILs.

\section{Experimental}

\subsection{Materials}

All of the reagents were analytical grade and used without further purification. 1-Methyl imidazolium, 1,2-dimethyl imidazolium, and 1-butyl bromide were purchased from Acros (Belgium). Formaldehyde, butyraldehyde, and other reagents were supplied by Tianjin Chemical Reagent Co., Ltd. IL 1-butyl-3methyl imidazolium hydroxyl $([\mathrm{bmim}] \mathrm{OH})$ was synthesized and purified according to the previously reported procedure. ${ }^{23}$ ILs 1butyl-3-methyl imidazolium formate ([bmim]HCOO), 1-butyl-3methyl imidazolium acetate ([bmim]Ac), 1-butyl-2,3-dimethyl imidazolium acetate ([bmmim]Ac), and 1-butyl-3-methyl imidazolium proline ([bmim]Pro) were synthesized and their basicities were characterized according to our previous work. ${ }^{25}$ The structures of these ILs were determined by Fourier transform infrared spectroscopy (FT-IR, Nicolet Nexus 870 FT-IR spectrometer (America), $\mathrm{KBr}$ coating), nuclear magnetic resonance ( ${ }^{1} \mathrm{H}-\mathrm{NMR}$ and ${ }^{13} \mathrm{C}-\mathrm{NMR}$, Mercury-Plus $400 \mathrm{MHz}$ (America), $\mathrm{D}_{2} \mathrm{O}$ as solvent for $[$ bmim $] \mathrm{OH}$ and $\mathrm{d}_{6}$ - DMSO for others), and electrospray ionization mass spectrometry (ESI-MS, ThermoFinnigan LCQ Deca XP Plus (America)). NMR, ion chromatography, and elemental analysis $^{24}$ show that the purities of these ILs exceed $97 \%$.

\subsection{TMP production, separation, and characterization}

The TMP used in this study was obtained through consecutive processes of Aldol reaction and a Cannizzaro condensation.

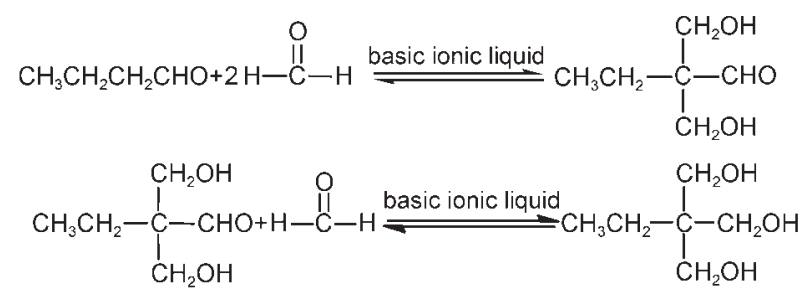

Typically, $0.02 \mathrm{~mol}$ butyraldehyde, $0.1 \mathrm{~mol}$ formaldehyde (measured as formaldehyde in $37 \%$ formalin), and a designated amount of basic IL catalyst were loaded into a $50 \mathrm{~mL}$ roundbottom flask. The mixture was stirred at $30{ }^{\circ} \mathrm{C}$ for $2 \mathrm{~h}$, and then stirred at $70^{\circ} \mathrm{C}$ for $4 \mathrm{~h}$. When the stirring time elapsed, the mixture of reactant and product was separated according to the following procedure.

Formaldehyde was first removed by steam distillation. Next, free butyraldehyde was extracted from the water soluble fraction using toluene $(20 \mathrm{~mL} \times 3)$. The large boiling point difference allowed the free butyraldehyde to be separated from toluene by distillation at reduced pressure. The coarse TMP product was collected from the water-soluble fraction by consecutively removing the water, $\mathrm{CHCl}_{3}$ crystallization, and drying at $50{ }^{\circ} \mathrm{C}$ for $3 \mathrm{~h}$ under reduced pressure. The resulting yellow solid was further recrystallized in ethyl acetate and dried at $50{ }^{\circ} \mathrm{C}$ under reduced pressure until a constant mass was achieved. The final TMP product was obtained as a white solid.

The physical-chemical properties and purity of the final product were characterized by FT-IR (Nexus 870 FT-IR spectrometer, $\mathrm{KBr}$ pelleting), ${ }^{1} \mathrm{H}-\mathrm{NMR}$ (Mercury-Plus $400 \mathrm{MHz}, \mathrm{D}_{2} \mathrm{O}$ ), ${ }^{13} \mathrm{C}-\mathrm{NMR}$ (Mercury-Plus $400 \mathrm{MHz}, \mathrm{D}_{2} \mathrm{O}$ ), and melting point measurements (X-4 digital micro melting point apparatus). The yield of the final product was measured by comparing the mass of the isolated TMP to the theoretical value based on the initial quantity of butyraldehyde. 


\subsection{Recyclability of IL}

After the careful separation of free $\mathrm{HCHO}$ and $\mathrm{HCOOH}$ and after the removal of butyraldehyde by extraction using toluene, the IL catalyst was extracted from the water soluble fraction using $\mathrm{CHCl}_{3}$ three times $(10 \mathrm{~mL} \times 3)$. The recovered IL was obtained by the efficient removal of $\mathrm{CHCl}_{3}$ at reduced pressure followed by drying at $70{ }^{\circ} \mathrm{C}$ under vacuum overnight. It was then used for the next run without further purification. The anion concentrations of the original versus the used ILs were determined on a Metrohm 792 basic ion chromatograph (Switzerland) according to the previously reported procedure. ${ }^{24}$

\section{Results and discussion}

\subsection{Characterization of the basic ILs}

All of the basic IL catalysts were intensively characterized by FT-IR, ${ }^{1} \mathrm{H}-\mathrm{NMR},{ }^{13} \mathrm{C}-\mathrm{NMR}$, and ESI-MS (the results were listed as follows). Determination of basic strength using the acid-dissociation constant $\left(\mathrm{p} K_{\mathrm{b}}\right)$ shows that the basic strength sequence of these $\mathrm{ILs}^{25}$ is $[\mathrm{bmim}] \mathrm{OH}>[\mathrm{bmim}]$ Pro $>[\mathrm{bmmim}] \mathrm{Ac}>[\mathrm{bmim}] \mathrm{Ac}>$ [bmim] HCOO.

\subsection{1 [bmim] $\mathrm{OH}$}

FT-IR: 3443, 2958, 2932, 2873, 1651, 1601, 1447, 1394, 1353, 1122, 871, 778, $694 \mathrm{~cm}^{-1} .{ }^{1} \mathrm{H}$ NMR (400 MHz, $\left.\mathrm{D}_{2} \mathrm{O}\right) \delta: 8.38(\mathrm{~s}$, 1H), 7.93 (s, 1H), $7.88(\mathrm{~s}, 1 \mathrm{H}), 4.71(\mathrm{t}, J=7.2 \mathrm{~Hz}, 2 \mathrm{H}), 3.27$ (s, $3 \mathrm{H}), 1.45(\mathrm{~m}, 2 \mathrm{H}), 1.21(\mathrm{~m}, 2 \mathrm{H}), 0.79(\mathrm{t}, J=7.2 \mathrm{~Hz}, 3 \mathrm{H}) .{ }^{13} \mathrm{C} \mathrm{NMR}$ (400 Hz, $\left.\mathrm{D}_{2} \mathrm{O}\right) \delta$ : 140.6, 134.8, 129.1, 48.9, 37.4, 33.8, 19.6, 13.4. ESI-MS: positive ion mode, $m / z=139(100 \%)\left[\mathrm{C}_{8} \mathrm{H}_{15} \mathrm{~N}_{2}\right]$; negative ion mode, $m / z=17(100 \%)[\mathrm{OH}]$.

\subsection{2 [bmim]Pro}

FT-IR: 3443, 2962, 2871, 2188, 1579, 1390, 1169, 1101, 833, 754, $623 \mathrm{~cm}^{-1} .{ }^{1} \mathrm{H}$ NMR (400 Hz, DMSO) $\delta: 9.54(\mathrm{~s}, 1 \mathrm{H}), 7.79(\mathrm{~s}$, $1 \mathrm{H}), 7.71(\mathrm{~s}, 1 \mathrm{H}), 4.14(\mathrm{t}, J=7.2 \mathrm{~Hz}, 2 \mathrm{H}), 3.83(\mathrm{~s}, 3 \mathrm{H}), 3.60(\mathrm{~s}$, $1 \mathrm{H}), 3.12(\mathrm{~s}, 1 \mathrm{H}), 3.01(\mathrm{br}, 1 \mathrm{H}), 2.87(\mathrm{~m}, 1 \mathrm{H}), 1.72(\mathrm{~m}, 3 \mathrm{H}), 1.57$ $(\mathrm{m}, 1 \mathrm{H}), 1.45(\mathrm{~m}, 1 \mathrm{H}), 1.37(\mathrm{~m}, 1 \mathrm{H}), 1.21(\mathrm{q}, 2 \mathrm{H}), 0.85(\mathrm{t}, J=7.2$ $\mathrm{Hz}, 3 \mathrm{H}) .{ }^{13} \mathrm{C}$ NMR (400 Hz, DMSO) $\delta: 177.0,137.6,124.0,122.7$, 63.1, 48.9, 47.5, 36.1, 31.9, 31.6, 26.5, 19.2, 13.7. ESI- MS: positive ion mode, $m / z=139(100 \%)\left[\mathrm{C}_{8} \mathrm{H}_{15} \mathrm{~N}_{2}\right]$; negative ion mode, $m / z=114(100 \%)\left[\mathrm{C}_{5} \mathrm{H}_{8} \mathrm{NO}_{2}\right]$.

\subsection{3 [bmmim]Ac}

FT-IR: 3432, 2962, 2884, 2133, 1640, 1572, 1405, 1347, 1247, $1124,1023,754,675 \mathrm{~cm}^{-1} .{ }^{1} \mathrm{H}$ NMR (400 MHz, DMSO) $\delta: 7.86$ (s, 2H), 4.15 (t, J=7.2 Hz, 2H), $3.81(\mathrm{~s}, 3 \mathrm{H}), 3.12(\mathrm{~s}, 3 \mathrm{H}), 2.63$ (s, $3 \mathrm{H}), 1.68(\mathrm{~m}, 2 \mathrm{H}), 1.54(\mathrm{~s}, 3 \mathrm{H}), 1.27(\mathrm{~m}, 2 \mathrm{H}), 0.88$ (t, J=7.2 Hz, $3 \mathrm{H}) .{ }^{13} \mathrm{C}$ NMR (400 MHz, DMSO) $\delta: 173.4,144.6,122.9,121.5$, 49.0, 47.3, 34.8, 31.6, 19.1, 13.7, 9.3. ESI-MS: positive ion mode, $m / z=153(100 \%)\left[\mathrm{C}_{9} \mathrm{H}_{17} \mathrm{~N}_{2}\right]$; negative ion mode, $m / z=60(100 \%)$ $\left[\mathrm{C}_{2} \mathrm{H}_{4} \mathrm{O}_{2}\right]$.

\subsection{4 [bmim]Ac}

FT-IR: 3429, 3151, 3086, 2957, 2873, 2186, 1564, 1467, 1391, 1326, 1164, 1008, 918, 762, 645, $613 \mathrm{~cm}^{-1}$. ${ }^{1} \mathrm{H}$ NMR $(400 \mathrm{MHz}$, DMSO) $\delta: 8.63(\mathrm{~s}, 1 \mathrm{H}), 7.97(\mathrm{~s}, 1 \mathrm{H}), 7.88(\mathrm{~s}, 1 \mathrm{H}), 4.20(\mathrm{t}, J=7.2$ $\mathrm{Hz}, 2 \mathrm{H}), 3.89$ (s, 3H), 1.77 (m, 2H), 1.23 (m, 2H), 0.85 (t, J=7.2 $\mathrm{Hz}, 3 \mathrm{H}) .{ }^{13} \mathrm{C}$ NMR (400 MHz, DMSO) $\delta$ : 165.7, 137.5, 124.0,
122.8, 48.6, 36.0, 34.8, 32.0, 19.2, 13.6. ESI-MS: positive ion mode, $m / z=139(100 \%)\left[\mathrm{C}_{8} \mathrm{H}_{15} \mathrm{~N}_{2}\right]$; negative ion mode, $m / z=60$ (100\%) $\left[\mathrm{C}_{2} \mathrm{H}_{4} \mathrm{O}_{2}\right]$.

\subsection{5 [bmim] HCOO}

FT-IR: 3443, 2962, 2884, 2793, 2715, 2110, 1639, 1584, 1471, $1169,1113,766,652,632 \mathrm{~cm}^{-1} .{ }^{1} \mathrm{H}$ NMR (400 MHz, DMSO) $\delta$ : 10.24(s,1H), $8.62(\mathrm{~s}, 1 \mathrm{H}), 7.98(\mathrm{~s}, 1 \mathrm{H}), 7.86(\mathrm{~s}, 1 \mathrm{H}), 4.19$ (t, $J=$ $7.2 \mathrm{~Hz}, 3 \mathrm{H}), 3.89$ (s, 3H), $1.75(\mathrm{~m}, 2 \mathrm{H}), 1.23(\mathrm{~m}, 2 \mathrm{H}), 0.86(\mathrm{t}, J=$ $7.2 \mathrm{~Hz}, 3 \mathrm{H}) .{ }^{13} \mathrm{C}$ NMR (400 MHz, DMSO) $\delta$ : 173.8, 138.3, 124.0, 122.7, 48.5, 31.5, 26.5 19.5, 13.9. ESI-MS: positive ion mode, $m / z=139(100 \%)\left[\mathrm{C}_{8} \mathrm{H}_{15} \mathrm{~N}_{2}\right]$; negative ion mode, $m / z=45(100 \%)$ $\left[\mathrm{CO}_{2} \mathrm{H}\right]$.

\subsection{Catalytic activities of IL catalysts}

The catalytic performances of basic ILs are first investigated. Table 1 shows that TMP production yield is only $28 \%$ without the use of a catalyst. However, when a basic IL is present, $74 \%$ to $82 \%$ isolated yield could be obtained. Generally, both the Aldol reaction and the Cannizarro reaction can be accelerated by alkali presence, hence, the addition of basic IL favors the production of TMP. Table 1 also demonstrates that the catalytic performances of the basic ILs are significantly influenced by their basic strengths, ${ }^{26}$ where stronger bases result in higher catalytic activity. For example, $[\mathrm{bmim}] \mathrm{OH}$ is the strongest basic IL and has the highest TMP yield, $82 \%$. According to the previous reports, ${ }^{27}$ the TMP production process utilizes a carbanion mechanism. Thus, stronger basicity indicates a higher density of carbanions resulting in higher TMP yield. Further investigation demonstrates that [bmim] OH also exhibits much better catalytic performance than traditional organic and inorganic alkalis, such as $\mathrm{NaOH}, \mathrm{Na}_{2} \mathrm{CO}_{3}, \mathrm{NaHCO}_{3}$, and $\mathrm{Et}_{3} \mathrm{~N}$. Moreover, compared with traditional alkalis, the desalination process is unnecessary for ILs. Therefore, ILs show

Table 1 Catalytic activities of basic ILs and conventional alkalis ${ }^{\text {a }}$

\begin{tabular}{|c|c|c|c|}
\hline Entry & Catalyst & Catalyst dosage $/ \mathrm{mol}$ & Yield of TMP $/ \%$ \\
\hline 1 & none & - & 28 \\
\hline 2 & {$[\mathrm{bmim}] \mathrm{OH}$} & 0.020 & 82 \\
\hline 3 & [bmim]Pro & 0.020 & 80 \\
\hline 4 & {$[\mathrm{bmmim}] \mathrm{Ac}$} & 0.020 & 77 \\
\hline 5 & {$[\mathrm{bmim}] \mathrm{Ac}$} & 0.020 & 75 \\
\hline 6 & [bmim] $\mathrm{HCOO}$ & 0.020 & 74 \\
\hline 7 & $\mathrm{Et}_{3} \mathrm{~N}$ & 0.020 & 65 \\
\hline 8 & $\mathrm{NaHCO}_{3}$ & 0.020 & 73 \\
\hline 9 & $\mathrm{Na}_{2} \mathrm{CO}_{3}$ & 0.020 & 75 \\
\hline 10 & $\mathrm{NaOH}$ & 0.020 & 80 \\
\hline 11 & {$[\mathrm{bmim}] \mathrm{OH}$} & 0.006 & 68 \\
\hline 12 & {$[\mathrm{bmim}] \mathrm{OH}$} & 0.010 & 72 \\
\hline 13 & {$[\mathrm{bmim}] \mathrm{OH}$} & 0.030 & 80 \\
\hline 14 & {$[\mathrm{bmim}] \mathrm{OH}$} & 0.040 & 75 \\
\hline 15 & {$[\mathrm{bmim}] \mathrm{OH}$} & 0.100 & 70 \\
\hline $16^{c}$ & {$[\mathrm{bmim}] \mathrm{OH}$} & 0.020 & 79 \\
\hline
\end{tabular}


great substitution potential for the traditional alkali catalyst in this process.

For homogeneous catalysts, larger catalyst dosages normally mean more active catalytic centers, resulting in higher catalytic performance. ${ }^{28-30}$ Therefore, a sharp increase in TMP yield was observed with increasing catalyst dosage from 0.006 to $0.020 \mathrm{~mol}$ (Table 1). However, formaldehyde and butyraldehyde could catalytically condense with each other and themselves in the presence of $[\mathrm{bmim}] \mathrm{OH}$. For example, more than $76.8 \%$ conversion (determined by gas chromatography flame ionization detector (GC-FID) analysis) was observed when $0.04 \mathrm{~mol}$ butyraldehyde and $0.02 \mathrm{~mol}$ [bmim] $\mathrm{bH}$ were heated at $80{ }^{\circ} \mathrm{C}$ for $5 \mathrm{~h}$. Namely, during the TMP production, heteronuclear condensation of butyraldehyde with $\mathrm{HCHO}$ competes with self-condensation. Due to steric hindrance, the smaller molecule, $\mathrm{HCHO}$, more readily attaches to the butyraldehyde molecule at low [bmim]OH concentrations. Nevertheless, when excess catalyst is present, the density of active carbanion intermediate of butyraldehyde increases significantly. As a result, both the heteronuclear condensation and self-condensation of butyraldehyde were promoted. Thus, the isolated yield of TMP was declined gradually when the added IL [bmim] OH was more than $2.0 \mathrm{mmol}$ (Table 1).

\subsection{Effects of reaction temperature and time}

Fig. 1 shows the effects of reaction temperature and time on TMP production. As shown in Fig.1(a), TMP yield significantly increases when the Cannizzaro temperature is elevated from 50 to $70{ }^{\circ} \mathrm{C}$. It is well known that condensation could be accelerated significantly at high temperature, resulting in high conversion rates and product yields. ${ }^{30}$ However, side reactions, such as dehydration and etherization of polyol, would also be accelerated. Therefore, no obvious increases in TMP yield are observed as temperature is increased above $70{ }^{\circ} \mathrm{C}$ (Fig.1(a)). Reaction time is also a significant factor for TMP production. Fig. $1 \mathrm{~b}$ shows that TMP yield sharply increases from $70 \%$ to $80 \%$ when the reaction time is extended from 2 to $4 \mathrm{~h}$. However, once thermodynamic equilibrium is reached (around $4 \mathrm{~h}$ ), TMP yield becomes independent of reaction time.

The influences of Aldol reaction temperature and time on the isolated yield of TMP were also studied (Fig.1(c, d)). Fig.1(c) demonstrates how the TMP yield increases sharply (73\% to $83 \%$ ) when the reaction temperature is increased from 20 to $30{ }^{\circ} \mathrm{C}$, and then plateaus upon increasing the temperature further. Fig.1(d) shows that the isolated yield of TMP is significantly influenced by the Aldol reaction time. The isolated yield of TMP gradually increases with prolonged reaction time. For example, less than $75 \%$ TMP yield is achieved without the Aldol process, but sharply increases to $82 \%$ when the reactants and catalyst are pretreated at $30{ }^{\circ} \mathrm{C}$ for $2 \mathrm{~h}$ (Fig.1(d)), suggesting that the Aldol condensation process is essential for efficient TMP production. However, increases in TMP yield are less significant at Aldol reaction times
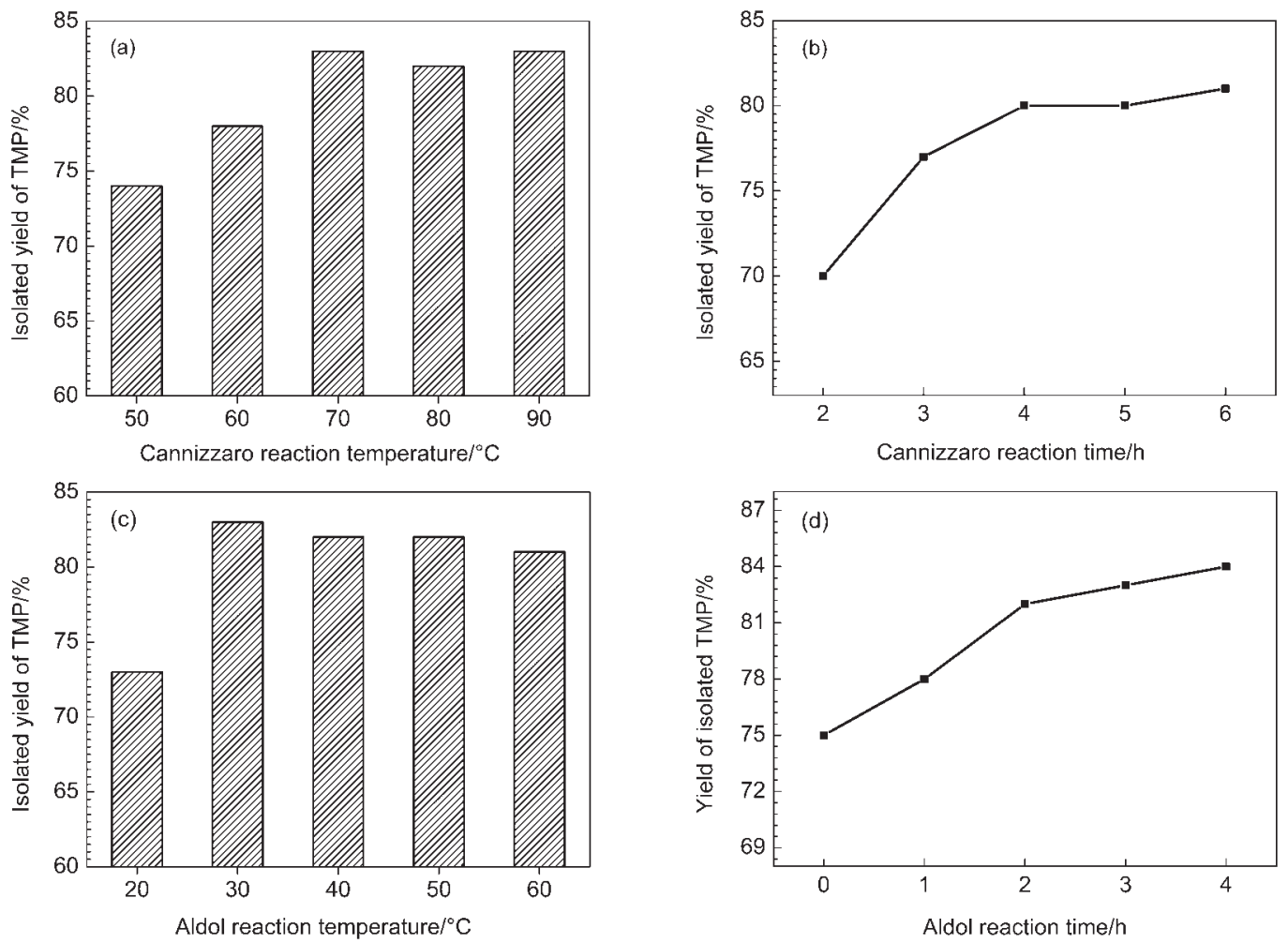

Fig.1 Effects of reaction temperature and time on the yield of TMP

(a) Cannizzaro condensation temperature, (b) Cannizzaro condensation time, (c) Aldol reaction temperature, (d) Aldol reaction time. Reaction conditions are as follows: $0.02 \mathrm{~mol}$ butyraldehyde, $0.1 \mathrm{~mol}$ formaldehyde (measured as formaldehyde in $37 \%$ formalin), and $0.02 \mathrm{~mol}$ [bmim] OH. (a) Cannizarro time of $5 \mathrm{~h}$, and Aldol temperature of $30^{\circ} \mathrm{C}$ for $1 \mathrm{~h}$; (b) Cannizarro temperature of $70^{\circ} \mathrm{C}$, and Aldol temperature of $30^{\circ} \mathrm{C}$ for $1 \mathrm{~h}$; (c) Cannizarro temperature of $70{ }^{\circ} \mathrm{C}$ for $4 \mathrm{~h}$, and $\mathrm{Aldol}$ time of $1 \mathrm{~h}$; (d) Cannizarro temperature of $70{ }^{\circ} \mathrm{C}$ for $4 \mathrm{~h}$, and Aldol temperature of $30^{\circ} \mathrm{C}$ 
greater than $2 \mathrm{~h}$. Hence, $2 \mathrm{~h}$ is considered to be an appropriate reaction time for Aldol condensation. In light of the abovementioned discussion, we can safely conclude that TMP production is temperature dependent. Compared with the Cannizzaro condensation, the Aldol reaction is much faster at any given temperature. Thus, the Cannizzaro condensation can be considered a stepcontrolled process for TMP production.

\subsection{Effect of dosage ratio of formaldehyde and butyraldehyde}

Reactant dosage ratio of formaldehyde to butyraldehyde was also examined. Fig.2(a) shows that TMP yield first dramatically increases and then gradually decreases, attaining a maximum at the reactant dosage ratio of $6: 1$. For example, TMP yield increases from $50 \%$ to $84 \%$ when the dosage ratio of formaldehyde to butyraldehyde is increased from 3:1 to 6:1. Yield then decreased to $75 \%$ when the feed of $\mathrm{HCHO}$ grew to ten times that of butyraldehyde. In our opinion, the dramatic increase can be attributed to the following: (1) increased reactant promotes heteronuclear condensation, and (2) dilution with the $37 \%$ HCHO solution inhibits self- condensation of butyraldehyde. However, too much HCHO solution causes a concentration reduction of both [bmim] OH and butyraldehyde, reducing TMP yield (Fig.2(a)).

\subsection{Recyclability of IL and butyraldehyde}

Recovery of the IL involves careful separation and removal of $\mathrm{CHCl}_{3}$ followed by drying at $70{ }^{\circ} \mathrm{C}$ under vacuum overnight. Our
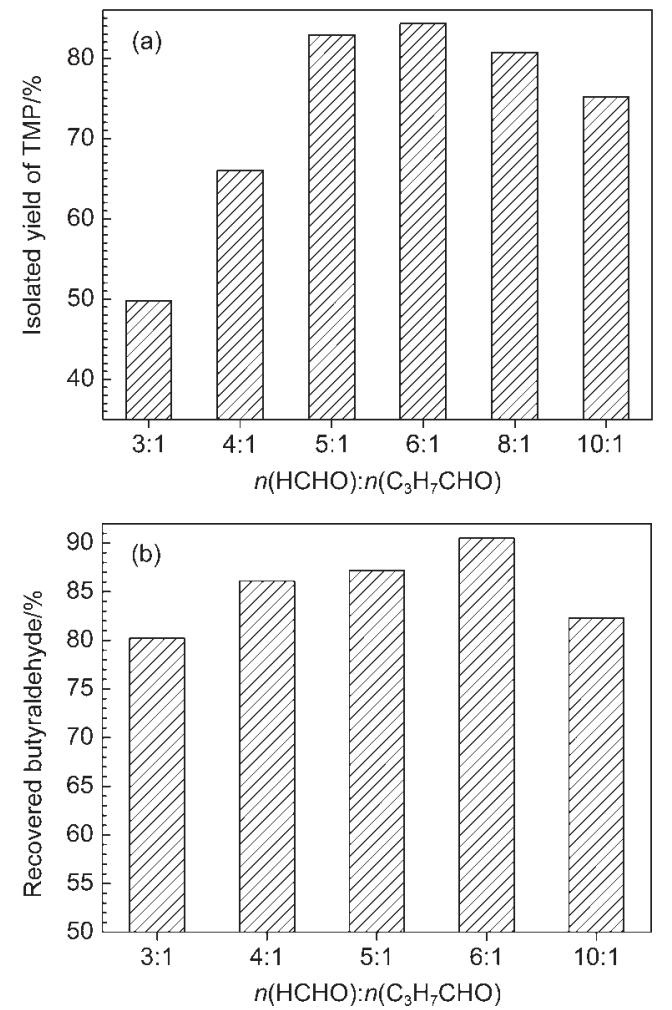

Fig.2 (a) Effects of molar ratio of the feedstock on TMP yield, and (b) the recyclability of free butyraldehyde

Reaction conditions are as follows: Aldol temperature of $30^{\circ} \mathrm{C}$ for $2 \mathrm{~h}$, and Cannizarro temperature of $70{ }^{\circ} \mathrm{C}$ for $4 \mathrm{~h}$ during reactions containing (a) $0.02 \mathrm{~mol}$ butyraldehyde, and (b) $0.2 \mathrm{~mol}$ butyraldehyde. results demonstrate that the IL catalyst is recyclable, achieving a TMP yield of $79 \%$ at optimized conditions after three runs (see the last entry of Table 1). The reduction of TMP yield cannot be attributed to the thermal decomposition of the IL catalyst, according to previous literature. ${ }^{19,21}$ The reduction is more likely attributed to weight loss during the separation process $(10.6 \%$ weight loss occurs after three runs). Additionally, $12.5 \%$ of the $\mathrm{OH}^{-}$groups are replaced by $\mathrm{HCOO}^{-}$(measured by ion chromatography) after three runs. This change also contributes to a reduction in catalytic activity since [bmim] HCOO demonstrates lower catalytic activity than [bmim] $\mathrm{OH}$ (Table 1 ).

Butyraldehyde is an important intermediate and feedstock for the fine chemical industry. Furthermore, this colorless liquid has an acrid smell and is flammable. ${ }^{32}$ Therefore, recycling butyraldehyde is necessary. Fig.2(b) shows that this chemical is recyclable, where greater than $80 \%$ of unreacted butyraldehyde can be successfully extracted by toluene and separated by distillation. Fig.2(b) also demonstrates that the extraction of this compound dramatically increases up to $90.7 \%$ when the molar ratio of $\mathrm{HCHO}$ to butyraldehyde is $6: 1$, followed by a drop-off in recyclability when the formaldehyde dosage ratio reaches 10:1. At low formaldehyde doses, not only is TMP produced, but also butyraldehyde self-condenses $(76.8 \%$ conversion during the selfcondensation process with $[\mathrm{bmim}] \mathrm{OH})$, as discussed above. However, a formaldehyde concentration that is too high dilutes the butyraldehyde, resulting in a reduction of extraction efficiency.

\subsection{Characterization of the final product}

Fig.3 shows the ${ }^{1} \mathrm{H}-\mathrm{NMR}$ spectrum of the final TMP product. The triplet peak at $\delta 0.79(3 \mathrm{H})$ is attributed to the methyl group of TMP. The chemical shifts at $1.24(2 \mathrm{H})$ and $3.44(6 \mathrm{H})$ are ascribed to the $\mathrm{CH}_{2}$ groups adjacent to $\mathrm{CH}_{3}$ and $\mathrm{OH}$, respectively. The hydroxyl shows a single peak at $\delta 4.70(3 \mathrm{H})$.

The ${ }^{13} \mathrm{C}$-NMR spectrum of the final TMP product was also investigated. The results shown in Fig.4 demonstrate that there are four carbons in the TMP molecule. The signal at 6.47 is assigned to $\mathrm{CH}_{3}$. The peak at 20.95 is attributed to the absorption from $\mathrm{CH}_{2}$. Quaternary carbon shows a signal peak at 43.22. The absorption peak at 62.13 is assigned to the carbon atom in $\mathrm{CH}_{2} \mathrm{OH}$. Both the ${ }^{1} \mathrm{H}-\mathrm{NMR}$ and the ${ }^{13} \mathrm{C}-\mathrm{NMR}$ spectra of our produced TMP show similar signals to the standard spectra of TMP, and they agree well with previously reported studies. ${ }^{1,26}$

FT-IR spectra were collected to further characterize the final TMP products (Fig.5). The produced TMP shows a similar absorption spectrum to the standard TMP spectrum. The absorbance at $3334 \mathrm{~cm}^{-1}$ is considered to be the characteristic absorption of hydroxyls. ${ }^{33}$ The peak at $1489 \mathrm{~cm}^{-1}$ suggests the existence of the primary alcohol $\left(\mathrm{CH}_{2} \mathrm{OH}\right)$. The absorbencies at 2934, 2910, and $2858 \mathrm{~cm}^{-1}$ are designated as the stretching vibrations of $-\mathrm{CH}_{2} \mathrm{OH}$, $\mathrm{CH}$, and $\mathrm{CH}_{2}$, respectively. ${ }^{34}$ The absorbencies at 1376,1292 , 1193 , and $782 \mathrm{~cm}^{-1}$ are characteristic peaks of alkyl groups, $\mathrm{CH}_{3}$, $\mathrm{CH}_{2}$, and $\mathrm{CH}^{35}$ The characteristic absorption peaks at 1064 and $1058 \mathrm{~cm}^{-1}$ are ascribed to the $\mathrm{C}-\mathrm{O}$ stretching vibration of primary alcohol. Noticeably, the characteristic infrared absorption of 


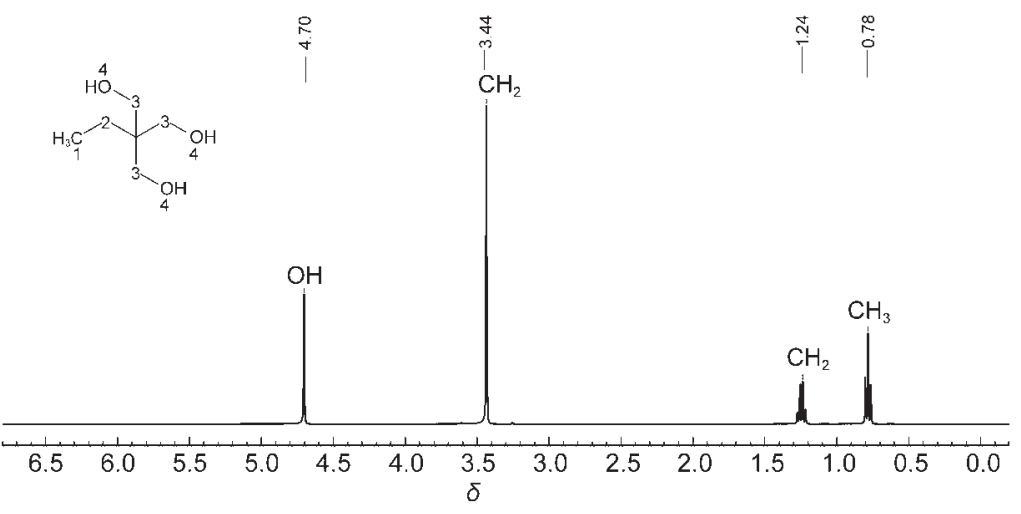

Fig.3 ${ }^{1}$ H-NMR spectrum of the final TMP product

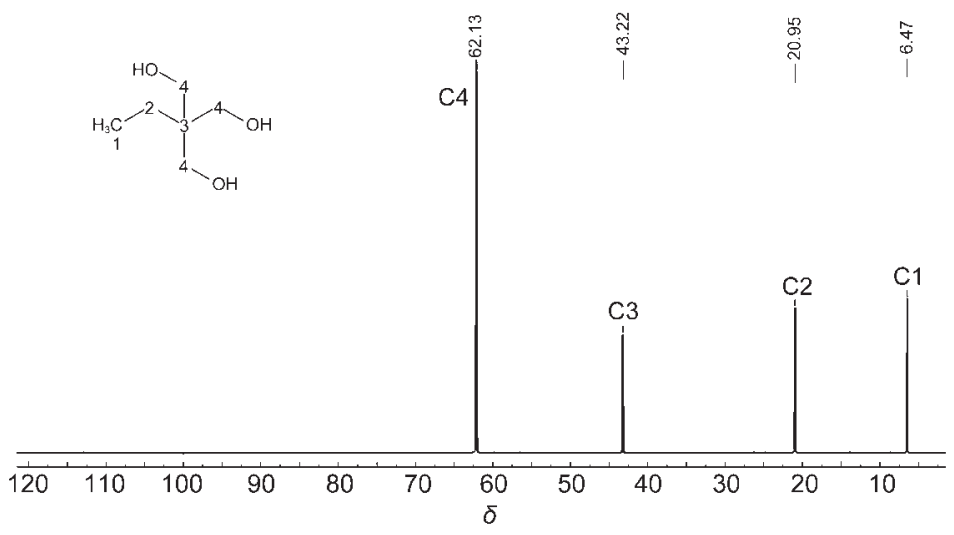

Fig.4 ${ }^{13} \mathrm{C}$-NMR spectrum of the final TMP product

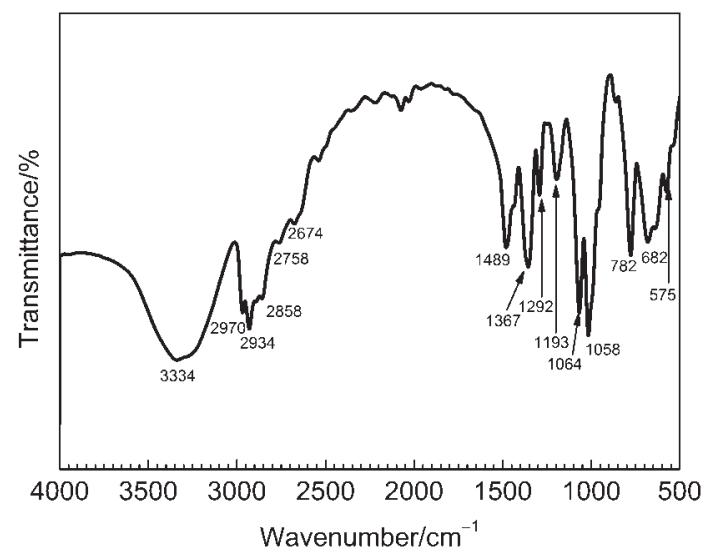

Fig.5 FT-IR spectrum of the final TMP product

$\mathrm{C}=\mathrm{O}$, which generally ranges from 1750 to $1700 \mathrm{~cm}^{-1}$, is not present. In light of these findings, in conjunction with the ${ }^{1} \mathrm{H}-$ NMR (Fig. 3) and ${ }^{13}$ C-NMR (Fig.4) results, we can safely conclude that the TMP produced by this basic IL catalytic process has high purity. Furthermore, the final TMP product has a narrow melting point between 58 and $60{ }^{\circ} \mathrm{C}$, in good agreement with previously reported melting points of TMP. ${ }^{1,26}$

\section{Conclusions}

In conclusion, an efficient and novel strategy for producing TMP is proposed using basic IL catalysts. The catalytic performance of the IL significantly depends on the basic strength, where higher basic strength results in higher catalytic activity. Under optimized conditions, isolated yields greater than $84 \%$ are attainable with the strongest basic IL, [bmim] OH. This yield was higher than that attained by conventional alkalis. Furthermore, both the $[\mathrm{bmim}] \mathrm{OH}$ and the butyraldehyde demonstrate good recyclability, after which, the IL showed slight activity loss (after three runs) while $90.7 \%$ of free butyraldehyde could be recovered. Moreover, this method has the advantage of avoiding the tedious and labor-intensive desalination process, which is necessary for traditional base catalytic processes. Therefore, this efficient process provides a promising and beneficial method for future production of TMP.

\section{References}

(1) Werle, P.; Morawietz, M.; Lundmark, S.; Sörensen, K.; Karvinen, E.; Lehtonen, J. Alcohols, Polyhydric. In Ullmann's Encyclopedia of Industrial Chemistry; Wiley-VCH Verlag GmbH \& Co. KGaA: Weinheim, Germany, 2008.

(2) Serra-Holm, V.; Salmi, T.; Multamäki, J.; Reinik, J.; MäkiArvela, P.; Sjöholm, R.; Lindfors, L. P. Appl. Catal. A: Gen. 2000, 198 (1-2), 207.

(3) Rantakylä, T. K.; Salmi, T.; Aumo, J.; Mäki-Arvela, P.; Sjöholm, R.; Ollonqvist, T.; Väyrynen, J.; Lindfors, L. P. Ind. Eng. Chem. Res. 2000, 39 (8), 2876. doi: 10.1021/ie990745h

(4) Rantakylä, T. K.; Salmi, T.; Kuusisto, J.; Mäki-Arvela, P.; Ollonqvist, T.; Väyrynen, J.; Lindfors, L. P. Ind. Eng. Chem. 
Res. 2002, 41 (3), 524. doi: 10.1021/ie001000a

(5) Zhang, Q.; Zhang, S.; Deng, Y. Green Chem. 2011, 13 (10), 2619. doi: $10.1039 / \mathrm{c} 1 \mathrm{gc} 15334 \mathrm{j}$

(6) Ning, H.; Hou, M. Q.; Yang, D. Z.; Kang, X. C.; Han, B. X. Acta Phys. -Chim. Sin. 2013, 29 (10), 2107. [宁 汇, 侯民强, 杨德重, 康欣晨, 韩布兴. 物理化学学报, 2013, 29 (10), 2107.] doi: 10.3866/PKU.WHXB201304172

(7) Yuan, X.; Lou, S. J.; Kou Y. Acta Phys. -Chim. Sin. 2010, 26 (4), 908. [苑 晓, 娄舒杰, 寇 元. 物理化学学报, 2010, 26 (4), 908.] doi: 10.3866/PKU.WHXB20100433

(8) Pinkert, A.; Marsh, K. N.; Pang, S. S.; Staiger, M. P. Chem. Rev. 2009, 109 (12), 6712. doi: 10.1021/cr9001947

(9) Gong, Y. Y.; Liu, M.; Jia, S. Y.; Feng, J. P.; Song, C. S.; Guo, X. W. Acta Phys. -Chim. Sin. 2012, 28 (3), 686. [公艳艳, 刘 民, 贾松岩, 冯建萍, 宋春山, 郭新闻. 物理化学学报, 2012, 28 (3), 686.] doi: 10.3866/PKU.WHXB201112292

(10) Zakrzewska, M. E.; Bogel-Lukasik, E.; Bogel-Lukasik, R. Chem. Rev. 2011, 111 (2), 397. doi: 10.1021/cr100171a

(11) Parvulescu, V. I.; Hardacre, C. Chem. Rev. 2007, 107 (6), 2615. doi: 10.1021/cr050948h

(12) Long, J.; Li, X.; Wang, L.; Zhang, N. Sci. Chin. Chem. 2012, 55 (8), 1500. doi: 10.1007/s11426-012-4633-7

(13) Li, Z.; Zhao, Y. W.; Han, F.; Yang, L.; Song, H. Y.; Chen, J.; Xia, G. C. Sci. Sin. Chim. 2012, 42 (4), 502. [李 筛, 赵应伟, 韩 峰, 杨 否, 宋河远, 陈 静, 夏春谷. 中国科学: 化学, 2012, 42 (4), 502.] doi: 10.1360/032011-727

(14) Zhu, Y. H.; Zeng, H. Y.; Li, S. S.; Lu, Z. X.; Ma, C. A. Acta Phys. -Chim. Sin. 2012, 28 (2), 421 . [朱英红, 曾红燕, 李珊 珊, 陆在祥, 马淳安. 物理化学学报, 2012, 28 (2), 421.] doi: 10.3866/PKU.WHXB201112122

(15) Hallett, J. P.; Welton, T. Chem. Rev. 2011, 111 (5), 3508. doi: $10.1021 / \operatorname{cr} 1003248$

(16) Ranu, B. C.; Banerjee, S. Org. Lett. 2005, 7, 3049. doi: 10.1021/ ol051004h

(17) Moreira, D. N.; Longhi, K.; Frizzo, C. P.; Bonacorso, G. H.; Zanatta, N.; Martins, A. M. Catal. Commun. 2010, 11, 476. doi: 10.1016/j.catcom.2009.12.001

(18) Xu, J.; Liu, B.; Wu, W.; Qian, C.; Wu, Q.; Lin, X. J. Org. Chem. 2006, 71, 3991. doi: 10.1021/jo0600914

(19) Yang, L.; Xu, L.; Zhou, W.; Li, L.; Xia, C. Tetrahedron Lett. 2006, 47, 7723. doi: 10.1016/j.tetlet.2006.08.103

(20) Siddiqui, I. R.; Srivastava, A.; Shamim, S.; Srivastava, A.; Rahila, M. A. W. S.; Abumhdi, A. A. H.; Srivastava, A.; Rai, P.
J. Mol. Catal. A Chem. 2014, 382, 126. doi: 10.1016/j. molcata.2013.10.026

(21) Li, J.; Sun, H.; Cai, X. C.; Dai, L. Y. Chin. J. Org. Chem. 2007, 27, 1296. [李 娟, 孙 辉, 蔡晓晨, 戴立益. 有机化学, 2007, 27, 1296 .

(22) Mamaghani, M.; Pourranjbar, M.; Nia, R. H. J. Sulf. Chem. 2014, 35 (1), 1. doi: 10.1080/17415993.2013.800061

(23) Mehnert, C. P.; Dispenziere, N. C.; Cok, R. A. Chem. Commun. 2002, 2, 1601.

(24) Li, X. H.; Duan, H. L.; Pan, T. J.; Wang, L. F. Chin. J. Anal. Chem. 2006, 34, S192. [李雪辉, 段红丽, 潘景添, 王乐夫. 分 析化学, 2006, 34, S192.]

(25) Chen, X. W.; Song, H. B.; Chen, P.; Wang, F. R.; Qian, Y.; Li, X. H. Acta. Chim. Sin. 2012, 70, 770. [陈学伟, 宋红兵, 陈 鹏, 王芙蓉, 钱 宇, 李雪辉. 化学学报, 2012, 70, 770.] doi: 10.6023/A1108223

(26) Abd Hamid, H.; Yunus, R.; Rashid, U.; Choong, S. T.; AlMuhtaseb, H. A. Chem. Eng. J. 2012, 200, 532.

(27) Smith, B. M.; March, J. March's Advanced Organic Chemistry; John Wiley \& Sons, 2009.

(28) Long, J.; Guo, B.; Teng, J.; Yu, Y.; Wang, L.; Li, X. Bioresour Technol. 2011, 102, 10114. doi: 10.1016/j.biortech.2011.08.043

(29) Zhao, Y.; Long, J.; Deng, F.; Xia, C.; Peng, J. Catal. Commun 2009, 10, 732. doi: 10.1016/j.catcom.2008.11.030

(30) Long, J. X.; Guo, B.; Li, X. H.; Wang, F. R.; Wang, L. F. Acta Phys. -Chim. Sin. 2011, 27 (5), 995. [龙金星, 郭 斌, 李雪 辉, 王芙蓉, 王乐夫. 物理化学学报, 2011, 27 (5), 995.] doi: 10.3866/PKU.WHXB20110506

(31) Clayden, J.; Greeves, N.; Warren, S. Organic Chemistry, 2nd ed.; Oxford University Press: London, 2012.

(32) Cornils, B.; Fischer, R. W.; Kohlpaintner, C. Butanals, In: Ullmann's Encyclopedia of Industrial Chemistry; Wiley-VCH Verlag GmbH \& Co. KGaA: Weinheim, Germany, 2000.

(33) Long, J.; Zhang, Q.; Wang, T.; Zhang, X.; Xu, Y.; Ma, L. Bioresour Technol. 2014, 154, 10. doi: 10.1016/j. biortech.2013.12.020

(34) Mayo, W. D.; Miller, A. F.; Hannah, W. R. Course Notes on the Interpretation of Infrared and Raman Spectra; John Wiley \& Sons: New Jersey, 2004.

(35) Silverstein, R. M.; Webster, F. X.; Kiemle, J. D. Spectrometric Identification of Organic Compounds, 7th ed.; John Wiley \& Sons: Westford, USA, 2005. 